ORIGINAL ARTICLE

\title{
Teaching Professionalism in undergraduate Medical Education
}

\author{
AMJAD ALI ${ }^{1}$, ASIM SHAFI $^{2}$, ARIF SIDDIQ ${ }^{3}$, MUHAMMED SALMAN SIDDIQ $^{4}$, RAB NAWAZ MALIK $^{5}, \mathrm{KANWAL} \mathrm{KHALID}^{6}$ \\ ${ }^{1}$ Associate Professor Anatomy Bakhtawar Amin Medical \& Dental College, Multan \\ ${ }^{2}$ Associate Professor of Surgery Bakhtawar Amin Medical \& Dental College, Multan \\ ${ }^{3}$ Professor Gynae \& Obs. Bakhtawar Amin Medical \& Dental College, Multan \\ ${ }^{4}$ Medical Officer, Bakhtawar Amin Medical \& Dental College, Multan \\ ${ }^{5}$ Assistant Professor Bakhtawar Amin Medical \& Dental College, Multan \\ ${ }^{6}$ Assistant Professor Anatomy, Bakhtawar Amin Medical \& Dental College, Multan \\ Correspondence to; Dr Amjad Ali, Email: amjadfrcs@gmail.com, Cell: 03370752070
}

\begin{abstract}
For the last many years, there have been speedy and far-reaching changes in health teaching. [1] Numerous innovative approaches of teaching professionalism have been established and executed since 1950's and engrossed on medicalexpertise. In this paper, we will observe teaching professionalism in health teaching, detailing the usages and tasks associated with diverse methods. The developments in bio medical technologies and skills have been primed to advance of teaching professionalism tools that expand the assessment of expertise.

Objective: To observe the Teaching Professionalism in undergraduate medical education in BADMC Multan Methodology: A cross sectional survey was conducted at BAMDC Multan from January 2020 to June 2020 after obtaining ethical approval from ECB. The data was collected through convenience sampling technique from 50 health educators teaching anatomy, medicine, Surgery and Gyane \& Obs. to undergraduate students by using unidentified questionnaire. Consent was taken from all participants before data collection. Data was entered and analyzed by using SPSS 21.

Results: Of the 50 health educators, $46(92 \%)$ reacted to the main phase of the overview, $48(96 \%)$ of medical educators have sound mentalities about their jobs and responsibilities, 42 (84\%) having disintegration of clinical polished methodology, $44(80 \%)$ have clinical instructors ethicists- subjecting one's personal responsibility to the interest of patients, $50(100 \%)$ sticking to high moral and good guidelines, $40(80 \%)$ responding to cultural necessities, 48 (96\%) displaying center humanistic qualities (e.g., compassion, uprightness, benevolence, dependability), 50 (100\%) can design demonstrable, 46 (92\%) have duplicates of educational plan materials utilized in courses identified with polished skill, 48 (96\%) use Simulations ,22 (44\%) can use Computer-based simulation, 40 (80\%) can create case generation techniques.

Conclusion \& Recommendations: From this study, it is concluded that only 22 health educators (44\%) can use Computer-based simulation, $40(80 \%)$ can create case generation techniques, $40(80 \%)$ responding to cultural necessities, 42 (84\%) having disintegration of clinical polished methodology that is very low bench mark in teaching professionalism. Extra exploration is needed, mainly if the teaching professionalism is used to make high stick verdicts (e.g., elevation and authorization).
\end{abstract}

Key Words: Health Educators, Ethical Committee Board, Bakhtawar Amin Medical \& Dental College, Multan

\section{INTRODUCTION}

There is a growing awareness, both inside and outside the clinical profession that the corporate change of the medical services framework threatens to undermine the polished skill of physicians. [2,3,4] The ascent of oversaw care and consumerism in medication have driven numerous to stress over changes both in physicians' mentalities about their jobs and responsibilities and in the practices they show in the day by day practice of medication. [5,6] Clinical management have become worried about a disintegration of clinical polished methodology, as a result of this effect, the mentalities and practices of rehearsing doctors, especially clinical workforce have on the professional advancement of clinical structures and inhabitant doctors. $[7,8]$ For a long time, the procurement of favorable to professional qualities and practices happened to a great extent through a casual interaction of socialization that stretched out from medical institutions through residency and fellowship preparing. [9, 10].Simulations is progressively being used in health teaching to confirm that examiners can determine assimilation of criterion information, services, and affect in a exact situation [11]
With the speedy expansion of bio medical technology over the last 50 years, has come its solicitation to teaching professionalism. [12] As in other spaces of teaching, the computer was first used to upkeep the management of huge scales transcribed checks by enabling recording and reporting. The cases used as part of simulations are more hard and costly to create MCQs and this has consequences for achievability. [13] It is more difficult for examiners to aspect correct and fakeresponses.

\section{METHODOLOGY}

A cross sectional survey was conducted at BAMDC Multan from January 2020 to June 2020 after obtaining ethical approval from ECB. The data was collected through convenience sampling technique from 50 health educators teaching anatomy, medicine, Surgery and Gyane \& Obs. to undergraduate students by using unidentified questionnaire containing questions related to medical educators' mentalities about their jobs and responsibilities, disintegration of clinical polished methodology, clinical instructors ethicists, subjecting one's personal responsibility to the interest of patients, sticking to high moral and good 
guidelines, responding to cultural necessities, displaying center humanistic qualities (e.g., compassion, uprightness, benevolence, dependability), design demonstrable, duplicates of educational plan materials utilized in courses identified with polished skill, Simulations, Computer-based simulation, case generation techniques, work base assessment \& info case based discussion techniques. Consent was taken from all participants before data collection. Data was entered and analyzed by using SPSS 21.

\section{RESULTS}

Of the 50 health educators, $46(92 \%)$ reacted to the main phase of the overview, 48 (96\%) of medical educators have sound mentalities about their jobs and responsibilities, 42 (84 \%) having disintegration of clinical polished methodology, 44 (80\%) have clinical instructors ethicistssubjecting one's personal responsibility to the interest of patients, 50 (100\%) sticking to high moral and good guidelines, 40 (80\%)responding to cultural necessities, 48 (96\%) displaying center humanistic qualities (e.g., compassion, uprightness, benevolence, dependability), 50 $(100 \%)$ can design demonstrable, 46 (92 \%) have duplicates of educational plan materials utilized in courses identified with polished skill, 48 (96\%) use Simulations ,22 (44\%) can use Computer-based simulation, 40 (80\%) can create case generation techniques.

The overview survey results are summarized in Table 1.

\begin{tabular}{|l|l|l|}
\hline Questionnaire/Variables & Frequency & Percentage \\
\hline $\begin{array}{l}\text { Sound mentalities about jobs and } \\
\text { responsibilities }\end{array}$ & 48 & $96 \%$ \\
\hline $\begin{array}{l}\text { Disintegration of clinical polished } \\
\text { methodology, }\end{array}$ & 42 & $84 \%$ \\
\hline $\begin{array}{l}\text { Clinical instructors ethicists- } \\
\text { subjecting one's personal } \\
\text { responsibility to the interest of } \\
\text { patients, }\end{array}$ & 44 & $80 \%$ \\
\hline $\begin{array}{l}\text { Sticking to high moral and good } \\
\text { guidelines, }\end{array}$ & 50 & $100 \%$ \\
\hline Responding to cultural necessities, & 40 & $80 \%$ \\
\hline $\begin{array}{l}\text { Displaying center humanistic } \\
\text { qualities (e.g., compassion, } \\
\text { uprightness, benevolence, } \\
\text { dependability), }\end{array}$ & 48 & $86 \%$ \\
\hline $\begin{array}{l}\text { Duplicates of educational plan } \\
\text { materials utilized in courses } \\
\text { identified with polished skill, }\end{array}$ & 46 & $92 \%$ \\
\hline Design demonstrables, & 50 & $100 \%$ \\
\hline Use of Simulations & 48 & $86 \%$ \\
\hline $\begin{array}{l}\text { Use of Computer-based simulation, } \\
40\end{array}$ & 22 & $44 \%$ \\
\hline Create case generation techniques. & 40 & $80 \%$ \\
\hline
\end{tabular}

\section{DISCUSSION}

The educational plan materials given by the health educators uncovered huge variety in the quantity of teachers covering the recognitions of demonstrable skill in at least of their courses. While around three quarters of the teachers covered the at recognition "stick to high moral and good norms," 40 tended to the property "react to cultural necessities and mirror a common agreement with the communities served"
A large portion of the express instructing of supportive of professionalism happened regardless of whether in a solitary course or in numerous courses.. The most widely recognized approach, utilized by all Health educators, was to consolidate different ideas of demonstrable skill where polished methodology is tended to in-straightforwardly. Mostly were unable to use Simulations, Computer-based simulations and to create case generation techniques.

Extra exploration is needed, mainly if the teaching professionalism is used to make high stick verdicts (e.g., elevation and authorization).

The survey provides significant evidences about teaching professionals abilities which are in actual practice with undergraduate students. The work-based professionalism approaches presented may not be suitable for high- stakes testing (e.g., licensure and certification) where correspondence over teaching professionalism is needed.

\section{CONCLUSION \& RECOMMENDATIONS}

From this study, it is concluded that only 22 health educators (44\%) can use Computer-based simulation, 40 (80 \%) can create case generation techniques, 40 (80\%) responding to cultural necessities, 42 (84 \%) having disintegration of clinical polished methodology that is very low bench mark in teaching professionalism. Extra exploration is needed, mainly if the teaching professionalism is used to make high stick verdicts (e.g., elevation and authorization).

\section{REFERENCES}

1. Sullivan WM. What is left of professionalism after managed care? Hastings Center Rep. 1999;29:7-13.

2. American Board of Internal Medicine. Project Pro- fessionalism. Philadelphia, Pa: American Board of In- ternal Medicine; 1995.

3. Brint S. In an Age of Experts: The Changing Role of Professionals in Politics and Public Life. Prince- ton, NJ: Princeton University Press; 1994.

4. Sullivan WM. Work and Integrity: The Crisis and Promise of Professionalism in America. New York, NY: Harper Collins; 1995.

5. Swick HM. Academic medicine must deal with the clash of business and professional values. Acad Med.1998;73:751-755.

6. Wear D. On white coats and professional devel-opment: the formal and hidden curricula. Ann Intern Med. 1998;129:734737.

7. Cruess RL, Cruess SR. Teaching medicine as a pro-fession in the service of healing. Acad Med. 1997;72:941-952.

8. Reynolds PP. Reaffirming professionalism throughthe education community. Ann Intern Med. 1994;120:609-614.

9. Hensel WA, Dickey NW. Teaching professional-ism: passing the torch. Acad Med. 1998;73:865- 870.

10. Tekian, A. (1999). Assessing communication, technical, and affective responses: Can they relate like a professional? In A. Tekian, C. H. McGuire, \& W. C. McGaghie (Eds.), Innovative simulations for assessing clinical competence (pp. 105-112). Chicago: Department of Medical Education, University of Illinois at Chicago.

11. Relman AS. Education to defend professional val-ues in the new corporate age. Acad Med. 1998;73:1229-1233.

12. Topping, K. (1998). Peer assessment between students in colleges and universities. Review of Educational Research, 68, 249-276. 